\title{
The practice and challenges of adopting information and communication technologies in Chinese higher education
}

\author{
Jember, Solomon Tadele $\triangle$ \\ Beijing Normal University, China (Solomontadele7@gmail.com)
}

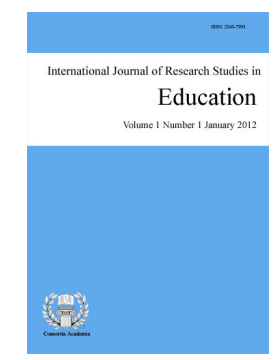

Accepted: 26 February 2021

ISSN: 2243-7703 Online ISSN: 2243-7711

OPEN ACCESS

\section{Abstract}

This review paper aims to analyze the practice and challenges of adopting information and communication technologies in Chinese higher education. The Information and communication technologies application in China education is expanding swiftly, which is positively promoted by the support of social enterprises and the development of educational resources. Information and communication technologies application into the educational system greatly influenced the Chinese higher education system; it is more convenient and efficient via Information and communication technologies than ever before. A large quantity of digital tools is adopted in the learning and teaching process. The content and form of higher education have altered to some extent. The Chinese government set the goals and policies of Information and communication technologies application in education in the purpose of systematically implementing Information and communication technologies in Chinese higher education. In this regard; a large quantity of digital tools is adopted in learning and teaching process. However, there is a range of challenges faced by Chinese higher education to adopt Information and communication technologies. These challenges include institutional structures, infrastructure and equipment, hardware-dominated approach, and teachers' lack of adequate skills. To this end, it is recommended to integrate information and communication technologies into the education system require the higher education institutions teachers and students needs to support adequate skills, thus contributing to improving the challenges of information and communication technologies in Chinese higher education.

Keywords: information and communication technologies; higher education institutions; adoption; higher education; classroom 


\section{The practice and challenges of adopting information and communication technologies in Chinese higher education}

\section{Introduction}

Higher education comprises all post-secondary education, training and research guidance in educational institutions such as universities that are authorized as institutions of higher education by state authorities. It includes all the activities in a given country deems to be higher education - not only those that take place within ordinary universities and graduate schools, but shorter term education and training courses (polytechnics, junior colleges, and various forms of technical specialty schools) that are 2-3 years in length, and even correspondence courses that make use of information technology and are targeted at a broad population of students (Brennan, 2008). As to Xiao et al. (2005), those higher educational intuitions have a great role for human knowledge and intellectual capital in economic growth and social development of a country in knowledge and economy.

Higher educational institutions have their own roles. For instance, it will contribute to developing human resources necessary for economic and social development. In the long run; higher education would fulfill the role of producing a government and private sectors. In other words, developing high-level human resources with the necessary knowledge and skills for economic and social development has been the most important role of higher education. Hence, it is becoming important to expand higher education so that a wide range of human resources can be developed and the entire society's level of knowledge can be raised. Higher education also helps create and diffuse knowledge in a knowledge society (UNESCO, 1998).

In particular, enhancing an individual's ability to apply knowledge and technical skills are extremely important to economic development. The knowledge and technology society demands are extremely varied. But at the same time, the speed of technological innovation has increased and the period of usefulness for particular knowledge and technology has shortened. Because of this, it is necessary to have a system for continually gathering and choosing among the knowledge and technology and renewing it, and further developing the opportunities for lifelong education (UNESCO, 2000).

Moreover, higher education would help to develop a healthy civil society and cultivating social cohesion. This means that a role in reforming the social system and cultivating social cohesion is also demanded of higher education. This can be accomplished through the production of the common asset of new knowledge, including the spread of democratic values and respect for multiculturalism, the promotion of political participation, the strengthening of civil society and promotion of democratic governance (Lawless et al., 2007).

Furthermore, higher education is a means to achieve self-realization for individuals. Concretely, people can improve their income and quality of life through increasing knowledge or skills and then expand on their own choices available in life, including those related to work life. In addition, lifelong education, which constantly renews individual knowledge and skills, needs to be guaranteed throughout the lifetime to respond to individual learning needs. Therefore, just as one should guarantee basic education for all, one should guarantee opportunities for higher education equally, based on individuals' hopes and abilities.

China has been forming a relatively complete system of modern higher education since the founding of the People's Republic of China in 1949. It has developed by assimilating experiences of higher education development from industrialized countries around the world and the former Soviet Union. In 2010, the enrollment of Chinese higher education exceeded 31.05 million students, making it the world's largest higher education system. In the same year, China's gross enrollment rate for higher education reached $26.5 \%$, higher than the world's average level, albeit by a small margin. China is devoted to transforming its heavy population burden into a human resource advantage. According to the Education for all indexes developed by international 
Practice and challenges of adopting information and communication technologies in Chinese higher education

organizations, China ranks relatively high among developing countries in terms of the education system. One of the most fundamental and significant changes is that China has developed into a country with the largest higher education system in the world (Guiren, 2015).

Teaching with technology today has been increasingly regarded as a 'pedagogical adventure' that involves teachers in a creative process of imagining, experimenting with and evaluating innovative approaches with technologies (Somekh, 2007). By the same token, Almonte et al. (2010) stated that in today's world where knowledge and information are becoming key factors in driving productivity, competitiveness and increased wealth and prosperity. Similarly, Osei (2013) mentioned that the role of ICT education in recent years has become policy spheres in many countries. ICTs are paving the way for new forms of communication and collaboration among students that are changing the work environment both for them and their teachers (Almonte et al., 2010). Higher education institutions have been undergoing transformations in response to a wave of education sector reforms and the promise of ICTs in teaching, research, and learning. As to Adam (2003), the fast growth and convergence of ICTs have also forced academic institutions to react to the new way of knowledge creation, management, and distribution. ICTs not only increased opportunities for the rapid information exchange that facilitates teaching, research, and lifelong learning, but they also led to the globalization of higher education. In most education circles, ICTs are regarded as a solution for the problem of having to do more with less, providing access to increasingly diverse demography of students and faculty and improving both the quality and quantity of educational content. Students and faculty members are not only expected to participate in the conventional "chalk and talk" teaching and learning process but they are also required to be part of the virtual knowledge enterprise. The creation of new types of education providers through ICTs has also begun to challenge traditional models that were adopted and put into practice throughout the world (Almonte et al., 2010).

Introduction of ICTs into higher education is not only about promoting access and communication but is also about stimulating the flow of electronic content (e-content) that promotes teaching and learning, including electronic learning (e-learning). Creating and promoting a content-rich e-learning environment that satisfies teaching and research needs is a daunting task even in the developed world (Osei, 2013).

As to Liu (2002), ICT education was to regard ICT as an essential factor in the educational system and to take full advantage of ICT in every field of the educational system in the purpose of accelerating the education modernization. According to Guiren (2015), Chinese higher education as understood in its modern sense originated in the late 19th century. $\mathrm{Li}$ (2005) pointed out that the Chinese government had paid much attention to the process of introducing and integrating ICT application into the higher educational system.

New technologies are being widely propagated as effective instruments to both erase differences between learners and learning communities and raise learning behaviors and outcomes to a new level of quality. This has been true, particularly, with regard to transplanting "modern" education into rural communities (Barbara, 2015). By making use of modern IT and giving full play to the talent advantages and the role of higher education institutions in knowledge and cultural dissemination and innovation, the Ministry of Education has organized higher education institutions to provide 1,000 public video-based courses covering the trends and latest achievements of domestic and foreign culture and technology. In accordance with the technical standards for the public sharing of resources, the established national open courses are being upgraded, and 5,000 high-quality public-sharing courses have been created. The public course sharing system has been perfected and optimized to substantially enhance its service capabilities (Guiren 2015). The following section will further elaborate on the methodology part:

\section{Methodology}

This paper review was done based on data which were found from different documents. Document analysis is a way of collecting data by reviewing existing documents. It is a form of qualitative research in which documents are interpreted by the researcher to give voice and meaning around an assessment topic (Bowen, 
Jember, S. T.

2009). This research is tried to investigate the practice and challenges of adopting information and communication technologies in Chinese higher education. The documents review is chosen because that is related to the feasibility of the topic. It examines a selection of recently published scholarly papers in peer-reviewed journals addressing the practice and challenges of adopting information and communication technologies in Chinese higher education. The next part will discuss the inter link between ICT and education system in China.

\section{Information and communication technologies (ICT) and education system in China}

The ICT application in China higher education can cast back to 1994 when the China Education and Research Network (CERNET) were set up. At the very beginning, CERNET developed slowly. Nevertheless, since 1999, the number of new students is tremendously growing due to the rapid expanding of China higher education which is the result of the policy to transform from Elite Higher Education to Mass Higher Education in China. Zhao (2003) pointed out that such expansion directly results in the development of ICT use in universities and colleges around China. According to $\mathrm{Wu}$ (2005), the roles of ICT in education are varying with the development of ICT education. Different impacts of ICT have been exerted on education including improving quality and equity of education, narrowing down of education between the developed and developing nations and generating the new instructional mode, which is online education.

Information and communication technologies (ICT) in China higher education has not developed as fast as those developed nations although $\mathrm{Li}$ (2005) pointed out that the Chinese government had paid much attention to the process of introducing and integrating ICT application into the educational system. In this regard, higher education institutions, year after year, earn an ever-increasing number of national science and technology prizes established by the Chinese government (Guiren 2015).

According to Li (2005), ICT education in China is treated as the result of educational 'Informationisation' which was defined by the Chinese government as the whole process of integrating ICT application into the educational system. suggested that the main contents of Educational 'Informationisation' include the establishment of a networked education environment which is digital and intellectualized, in such education environment, a new platform open to any users without limitation should be set up, all the resources of learning and teaching could be shared and exchanged on this platform, New instructional modes and rules will be generated and run on this platform (Liu ,2002).

According to Hepp et al. (2004) important roles of ICT are pedagogical, culture, social, professional and administrative. It is obvious that ICT has taken an active part and played an increasingly dominant role in China educational system. Communication in education is more convenient and efficient via ICT than ever before. A large quantity of digital tools is adopted in learning and teaching. CERNET was set up so that resources of learning and teaching of all the subjects could be easily shared between teachers and students through ICT. It changes the traditional education mode and rules. And it also supports and improves the development of Students Learning Support Service in China. According to Wu (2005) due to the ICT application into the educational system, China higher education has been greatly influenced. The content and form of higher education have altered to some extent. The Chinese government set the goals and policies of ICT application in education in the purpose of systematically implementing Chinese Educational Informationisation'. Till now, remarkable achievements have been gained in ICT application into education though there still exist problems that need to be solved (Hepp et al.,2004).

According to Li (2005) up, today's major achievements of ICT application in China education is expanding swiftly, which is positively promoted by the support of social enterprises and the development of educational resources. About $70 \%$ of all the colleges have built a campus network. The development of educational resource and the modern education experiment have made some progress. Many departments have developed educational resource warehouses for materials including web-based courses and other courseware. The online-education

12 Consortia Academia Publishing (A partner of Network of Professional Researchers and Educators) 
Practice and challenges of adopting information and communication technologies in Chinese higher education

school (OES) has been steadily developed and is far more prosperous at present by contrast with the situation at its birth in 1999. In short, considerable progress has been achieved in both the hardware side and the software side of the ICT application in China educational system (Li, 2005)

\subsection{Policy directions regarding ICT in Chinese higher education}

According to Marathe (2017), Information and communication technologies (ICT) is a diverse set of technological tools and resources used to communicate and to create, disseminate, store and manage information. Currently, there is worldwide recognition of the effective role of ICTs in addressing some of the constraints of the tertiary education system (Osei, 2013). Information and communication technologies (ICT) have become commonplace entities in all aspects of life. According to Nisar (2011), the era of Information Communication Technology, so to perk up educational it is indispensable to implement the ICT in Education sector. A student can perform well as a resulting of using ICT to support their learning. It helps the students to augment their knowledge, skills, and to improve their learning skills (Osei, 2013).

ICT encourage students to take responsibility for their own learning and offers problem-centered and inquiry-based learning which provides easy access and information based resources (Marathe, 2017). ICT can be multi-media for instructional delivery. Instructional content can be delivered in textual, audio, visual, and audio-visual forms.

Education policymakers have been formalizing ICT policies as part of educational renewal and reform for almost four decades. At the international level, policy for integrating ICT for development was first formulated in the Millennium Development Goals (MDGs) Target 8.F, which states that "in cooperation with the private sector, make available the benefits of new technologies, especially information and communications" (United Nations, 2000,2012). Moreover, while not mentioned explicitly in the Education for All goals, it is arguable that ICT plays a pivotal role in achieving these goals, including broadening access, eliminating exclusion, and improving quality (UNESCO, 2000).

To support teaching and learning and education management, a variety of ICTs including television, computers and the internet continue to require a more stable energy source. The integration of ICT into schools requires electricity (e.g. grid/mains connection assisted instructional approaches may be implemented, ranging from the use of radio or television to computers, the internet and newly-emerging mobile devices. While newer battery-operated ICTs are emerging, in addition to mobile devices that may be recharged off-site, the wind, water, solar or fuel-powered generator, etc.), this is regularly and readily available (UNESCO, 2014).

In order to provide advanced forms of ICT-assisted instruction, including computer-assisted instruction and Internet-assisted instruction, sufficient computer resources, and Internet connectivity must be established, keeping pace with demand based on enrolment. The learner-to-computer ratio refers to the mean number of learners sharing a single computer available for pedagogical use in national, aggregate education systems (UNESCO, 2014). According to Adam (2003) preparing schools to accept ICT includes constructing a policy to enable certain basic infrastructure such as electricity, phone lines, school buildings, safe and secure environment, and insurance are available. Certain minimum infrastructure requirements are important to enable the use of ICT.

Procuring and installing the technology any policy statement needs to address the type of hardware, operating systems, and software that would be conducive to school environments in the county. This includes models for efficient, affordable, quality access to the Internet for schools. Such elements would also need to set student-computer ratio targets and technical support mechanisms. Training teachers to use ICT Teachers need to understand the application of ICT to support their teaching and administration. Therefore, policy should identify ways of improving teacher capacity in the use of ICT as well as their specific integration into teaching systems and pedagogical models. The policy should also outline the type of additional staff required to support computers and related technologies (Adam,2003). 
Another reason could be that teachers lack knowledge/experience of and familiarity with ICT. It is important that teachers have knowledge of the use of the Internet in planning/teaching for two reasons. First, a teacher who makes use of the Internet as an additional teaching tool will most like security and confidence learn his/her students' respect and regard, which in turn will give the teacher a sense of security and confidence (Almonte et al., 2010).

Second, lesson/course planning and teaching will most likely benefit from the teacher's knowledge and use of the Internet in his/her daily work the positive aspects of the use of the Internet on learning outside the classroom, he states that many researchers propose that this new technology might come to change the nature of education and learning completely (Almonte et al., 2010).

There are also other aspects to take into consideration the use of the internet as an additional planning/teaching tool. First, most likely, all teachers and their students do not have the same access to computers/the internet in the school. Hence, the use of the Internet in planning/teaching might be prevented by circumstances outside the teacher's control. Second, the Internet might not be equally applicable in planning/teaching for all teachers (Adam 2003). The success of ICT-based education depends upon the teacher's ability to keep pace with the developments since teachers are responsible for quality control, improvement of learning and the aggregate effectiveness of the learning process (Marathe, 2017).

Higher education institutions, year after year, earn an ever-increasing number of national science and technology prizes established by the Chinese government (Guiren, 2015). China implements a push style technology policy; and students of this country influence the adoption of information technologies in their families especially communication technologies (Xiao et al., 2005). The Internet has the potential of making teaching more fun and interesting, and thus to increase students' motivation to learn. As access to higher education to the younger population is expanding, China is also becoming the major players for high-end knowledge labor forces. Given that ICT plays important role in improving higher education.

As to Barbara (2015) in China, new technologies are being widely propagated as effective instruments for erasing differences between learners and learning communities, particularly with regard to transplanting "modern" education into rural communities. The novelty of 21 st century ICT, however, tends to obscure the fact that these techno-optimist beliefs date back to attempts in the early 20th century to uplift rural China through the implementation of modern technologies (Barbara, 2015).

According to Xiao et al. (2005), information technology service sector in China has been advancing at a fascinating speed, in recent times; there has been rapid growth with ICT adoption in higher education in China. Practitioners and policymakers assume that the newly promoted technologies, by virtue of their novelty, will automatically transform and improve learning both in and outside the classroom (Barbara, 2015). New technologies are being widely propagated as effective instruments to both erase differences between learners and learning communities and raise learning behaviors and outcomes to a new level of quality. This has been true particularly with regard to transplanting "modern" education into rural communities.

In Chinese strategy documents, informatization has ascribed all sorts of powers and effects, among them economic growth, the effectiveness of political and administrative rule, military strength, enhanced national security, environmental protection, provision of health services, facilitation of commerce, and cultural revival. Informatization is also presented as an educational undertaking, not only by generally teaching ICT skills but also by making it possible, through ICT, to educate "distant" parts of the population, such as rural communities and migrant workers (MOE, 2006). The underlying assumption is that ICT leads to modernization by default (Zhao \& Xu, 2010).

As has been argued, in the past, "change" primarily meant improvement through increasing a nation's "productive capacity," which was seen as the formula for economic success and thus national survival/revival. In the policy papers on ICT development, and under the banner of the emerging "knowledge economy",

14 Consortia Academia Publishing (A partner of Network of Professional Researchers and Educators) 
Practice and challenges of adopting information and communication technologies in Chinese higher education

"productive capacity" has been strategically replaced by "creative capacity," the core ingredient in 21 st-century economies (Barbara, 2015). Chinese policymakers and educationists are of course not alone in their euphoric appraisal of the blessings and powers of ICT in education.

\subsection{The adoption of ICT the context of Chinese higher education classroom}

The processes of ICT incorporation in educational institutions must take into account educational, organizational, and infrastructure-related aspects, as a result of the comparative review of six international frameworks (Wirth, 2006). Educational Dimension: It is the core of ICT incorporation, including aspects related to the Pedagogical model, training strategies, the expansion of offerings, and the quality of educational processes are among the aspects included here.

Organizational Dimension: Deals with the processes and procedures on which stand the HEI's management, organization and daily running, analyzing if it has the necessary organizational structure to guarantee that the ICT use and development procedures are clear and flexible. It includes aspects such as support from directorship, agents in charge, and evaluation. Also must be considered within the organizational dimension, vision and ICT strategic planning aspects, economic and funding aspects, and cultural aspects, that is, the way that values, beliefs and practices in the involved social groups are affected.

Infrastructure and Equipment Dimension: It concentrates on long-term, sustainable disposal of a stable and functional technological environment, validating how the technologic infrastructure has been integrated and implemented in the HEI, which services of technologic support are offered, and how technologic quality is defined and guaranteed. It includes aspects such as technical support, eventual use of freeware, and choice criteria (Wirth, 2006).

ICT can also be used to support teachers who lack adequate skills and content knowledge, thus contributing to improving the quality of learning. UNESCO (1991) noted that many teachers who are hesitant to sit in classrooms or feel they are too old for the formal education system would find the interactive and asynchronous nature of ICT helpful for their professional development (Oseio,2013). The main role of teachers will not be to transmit information and culture, but rather to act as experts and leaders to motivate learning (Marathe, 2017). As to Nisar et al. (2011), PowerPoint and other visual technologies have become persistent in schools. Adoption of these technologies is perceived as a necessary - or, at the very least, an educationally appropriate, even though systematic examination of their use is relatively recent (Reedy, 2008). Teacher use of computer-mediated communication in the future will only be a success if the link between the possibilities of and teacher practice becomes clearer.

Policy Processes for a Systemic Approach any effort to integrate ICT into the education system requires the leadership of the government and the education ministry, working together with other relevant ministries (Almonte et al., 2010). This leadership must have a clear vision of why the government is enabling the use of ICT within the various sectors of the education system and the type of society it hopes to achieve by doing so. It also must have a clear vision of the mechanism that the government intends to use to implement ICT. This vision then needs to be integrated with national policies.

David Walker, in an article in the Higher Education Policy Journal, noted "three pre-conditions for a successful introduction of new information technologies into an education system:

$>$ An appreciation by government of the financial, resource and operational requirements and the resulting consequences;

$>$ A commitment by the government to give time and take responsibility for decision-making and implementation strategies;

$>$ A commitment to a policy of an integrated support service encompassing teacher and technician 
training, curriculum and assessment - together with software and hardware provision."

This appreciation, commitment and policy process has been undertaken in various developed and, increasingly, developing countries. Educational institutions should train teachers who are technology-competent and who effectively use and integrate technology into their teaching activities (Yasemin, 2008). The Chinese government has initiated a significant investment in the provision of information and communication technologies (ICT) in higher education (Ling Li, 2014).

Regardless of the quantity of technology placed in classrooms, the key to how those tools are used is the instructor. The majority of instructors believe technology usage is important for teaching, however, lack confidence and understanding during the integration process. Furthermore, instructors should possess the skills and competencies essential for designing, delivering and evaluating instruction (Gülbahar, 2008). Teachers are starting using ICT, even though no evidence was found that these teachers have a more positive degree of technological innovativeness. The challenge for teachers is to integrate ICT not only for supportive tasks but for teaching purposes as well. Nevertheless, computer networks offer enormous challenges for teaching and learning (Braak, 2000). Given the importance of access to technology, technology-competency and effective integration of technology, an understanding of how instructors and pre-service teachers perceive technology can help institutions of higher education to successfully integrate, in relation with the current ICT usage (Gülbahar, 2008).

Desiring technology-competent teachers for 21 st century classrooms, we have to inquire about the utilization of technology in teacher education institutions (Yildirim, 2000). Understanding the factors contributing to the utilization of technology and the possible relations between these factors will lead us to educate technology-competent teachers. According to Nisar, et al, (2011) powerful learning environments, rich contexts, and authentic tasks are presented to pupils. Many teachers apply several elements of powerful learning environments in their classes. Chances of using open-ended ICT applications, which are expected to contribute to the power of learning environments, were greater with teachers who created powerful learning environments for their pupils, and when there were more computers available to pupils. Moreover, teachers' skills with regard to the use of ICT as a means to support powerful learning environments should be fostered (Smeets, 2004).

Appropriate and improvised content ranging from learning materials such as textbooks, journals, web pages, video, television, radio, audiotape, and multimedia packages to learning support tools such as study guides, exam sheets, worksheets, laboratory manuals, and field exercises are in short supply in higher education institution (Adam, 2003).

\section{Challenges of implementations ICT in Chinese higher education}

According to Wu et al. (2016) as information and communication technology (ICT) continues to develop, it is essential for teachers to acquire the ability for teaching with ICT. In China, new higher education teachers often lack teaching experience because there are limited teaching opportunities during their postgraduate studies. This status quo may compromise the quality of teaching and learn in higher education institutions. Evaluation of new HE teachers' professional development in teaching with ICT should focus on not only short-term learning satisfaction but also long-term teaching and learning impacts in HE settings (Lawless \& Pellegrino, 2007; Stes et al., 2013)

ICT had a positive effect on new HE teachers' perception of ICT in terms of usefulness and motivation to use ICT and intention to integrate ICT for future teaching practice. However, teachers' perception of easy-to-use ICT was relatively weak (Wu et al., 2016). The motivation to use ICT was one significant predictor of intention to integrate ICT in teaching practice. Teacher candidates with more technical knowledge will have more knowledge of pedagogy and content. Therefore, in order to explain the degree of teachers' commitment and engagement to ICT-supported pedagogical change, it is necessary to understand their general interest and motivational factors as a collective group in a given academic community ( $\mathrm{Li}, 2014)$. 
As to $\mathrm{Wu}$ et al (2016), finding seems to indicate new HE teachers with a strong affinity toward ICT would have been more inclined to implement ICT into future practice, Perceived usefulness to be the well-established predictor of teachers' intention to integrate ICT in teaching. For the impacts level, many new HE teachers indicated that they were impressed with the blended learning approach and actually adopted this pedagogical approach in their teaching practice. Both these teachers and their department heads found students became more engaged in blended learning and performed better.

Several culturally-anchored factors play a significant role in how teachers perceive, perform and persist in ICT-supported teaching activities. The addressed teachers' ICT-related beliefs and behaviors are further justified as the visible symptoms of a deeply rooted cultural impact, which eventually hindered the university's efforts to change. The cultural barriers to ICT integration identified for a reformulation of the institutional culture into one that fosters teachers' ICT adoption and exploration of innovative pedagogies that impede teachers' adoption of technologies, so as to manage more efficient change ( $\mathrm{Li}, 2014)$.

Preparing young adults to meet future challenges is a major mission of higher education. In recent years, China's higher education system has been in a transition period, targeting innovative modeling of talent cultivation for the new demands of an emerging knowledge society. This reform is faced with an array of challenges that have long been existing in the higher educational system: the hierarchical nature of institutional structures, which has constrained the dynamics of pedagogical innovations; large blended classrooms, which have suffered from a lack of interactivity; the teacher-dominated pedagogy which reinforces the negative effects of passive non-participatory learning; and the examination-oriented knowledge transformation model, which fails to cultivate students' critical thinking and problem solving skills(Ling $\mathrm{Li}$,2014). The ICT-supported constructivist pedagogies require a huge amount of preparatory work from teachers: it requires sophisticated pedagogical planning, diverse teaching resources, and creative assignment design (Li, 2014).

When educational practitioners realized the weaknesses of the hardware-dominated approach, some remedial strategies were implemented to refine the effectiveness of ICT in education, e.g., facilitating ICT integration in education, teacher training, and designing and developing educational resources, which became the second stage of ICT's evolution in education. The effectiveness of ICT in education has considerably improved, teachers' competence of ICT has been strengthened, and the traditional teaching and learning approach has been significantly refined (Liu et al., 2007; Zhang, 2007).

\section{Conclusion}

Higher education has entered a new stage of providing more access to the general public, realizing the expected developmental goal in the first decade of the 21 st century in China. Higher education institutions play an increasingly important role as the major driving force in basic and advanced technology research, and their capacity for promoting socioeconomic development and solving key national scientific and technological issues has been strengthened considerably. The use of communications and information technologies in education development and delivery is vital for educational institutions are to achieve competitive success in the international market for higher and professional education. It encourages students to take responsibility for their own learning and offers problem-centered and inquiry-based learning which provides easy access and information based resources. ICT can be multi-media for instructional delivery. Instructional content can be delivered in textual, audio, visual, and audio-visual forms. Regardless of the quantity of technology placed in classrooms, the key to how those tools are used is the instructor. Sometimes instructors believe technology usage is important for teaching, however, lack confidence and understanding during the integration process. The important roles of ICT are pedagogical, culture, social, professional and administrative. It is obvious that ICT has taken an active part and played an increasingly dominant role in China educational system. Communication in education is more convenient and efficient via ICT than ever before. A large quantity of digital tools is adopted in learning and teaching of all the subjects could be easily shared between teachers and students through ICT. ICT changes the traditional education model and rules in China Higher Education. 
Nowadays, ICT has been commonly useful to education. Such application has added specific attention from people all over the world for it is an especially strong power that has brought about global education revolution. In China ICT application in higher education is one of the most protuberant issues to which the professionals in educational fields have paid more attention. In ICT the implication for learners it encourages students to take responsibility for their own learning and offers problem-centered and inquiry-based learning which provides easy access and information based resources. Practitioners should possess the skills and competencies essential for designing, delivering and evaluating instruction. In addition to that for promoting socioeconomic development and solving key national scientific and technological issues has been strengthened considerably. Administrators must take assessment that will be determined the proper equipment, support infrastructure, material resources, human resource, and structure to adopt it

\section{References}

Adam, L. (2003). Information and communication technologies in higher education in Africa: Initiatives and challenges. Journal of Higher Education in Africa, 1(1), 195-221.

Almonte, D. M., Andreu, B. H., \& Rejas, P. L. (2010). Information technologies in higher education: Lessons learned in industrial engineering. Educational Technology \& Society, 13(4), 140-154.

Barbara, A. (2015). (Dis)empowering technologies: ICT for education in China, past and present. Chinese Journal of Communication, 8(1), 59-77. https://doi.org/10.1080/17544750.2014.990909

Brennan, J. (2008). Higher education and social change. Higher Education, 5(3), 381-393. https://doi.org/10.1007/s10734-008-9126-4

Delgado-Almonte, M., Andreu, H. B., \& Pedraja-Rejas, L. (2010). Information technologies in higher education: Lessons learned in industrial engineering. Journal of Educational Technology \& Society, 13(4), 140-154.

Du Toit, J. (2015). Teacher training and usage of ICT in education: New directions for the UIS global data collection in the post-2015 context. UNESCO Institute for Statistics.

Guiren, Y. (2015). Education in China. Cengage learning.

Gülbahar, Y. (2008). ICT usage in higher education. A Case study on preservice teachers and instructor. The Turkish Online Journal of Educational Technology, 7(1).

Information Paper No. 22. (2014). Information and communication technology in education in Asia: A comparative analysis of ICT integration and e-readiness in schools across Asia. UNESCO Institute for Statistics.

Lawless, K. A., \& Pellegrino, J. W. (2007). Professional development in integrating technology into teaching and learning: Knowns, unknowns, and ways to pursue better questions and answers. Review of Educational Research, 77(4), 575-614. https://doi.org/10.3102/0034654307309921

Li, L. (2014). Towards a cultural framework to understand teachers. ICT adoption: A case study. Educate, 14(2), 29-43.

Marathe, R. A. (2019). Role of ICT in higher education in global era. International Journal on Recent and Innovation Trends in Computing and Communication, 5(11), 44-46.

MOE. (2006). 2006-2020 Development strategy for the nation's informatization in the years 2006-2020 [nian guojia xinxihua fazhan zhanlüe]. Zhongbanfa.

Nisar, M. W., Munir, E. U., \& Shad, S. A. (2011). Usage and impact of ICT in education sector. A study of Pakistan. Australian Journal of Basic and Applied Sciences, 5(12), 578-583.

Nortey, P. N. O. (2019). Psychosocial correlates of psychological wellbeing among clergy of the Presbyterian Church and the Church of Pentecost in Accra. Doctoral dissertation, University of Ghana.

Osei, K. (2013). The role of ICT in higher education in Ghana [Masteral Thesis]. University of Bradford.

Osorio, L., Cifuentes, G., \& Rey, G. (2011). ICT incorporation in higher education: E-maturity in the Plan EsTIC Project. In Educación paraelsiglo XXI: Aportes del Centro de Investigación y Formación en Educación

18 Consortia Academia Publishing (A partner of Network of Professional Researchers and Educators) 
(Vol. 2). Bogotá: Uniandes.

Schulte, B. (2015). (Dis) Empowering technologies: ICT for education (ICT4E) in China, past and present.

Chinese Journal of Communication, 8(1), 59-77. https://doi.org/10.1080/17544750.2014.990909

Stes, A., Maeyera, S. D., Gijbelsa, D., \& Petegem, P. V. (2013). Effects of teachers' instructional development on students. Study approaches in higher education. Studies in Higher Education, 38(1), 2-19. https://doi.org/10.1080/03075079.2011.562976

Wirth, M. A. (2006). An analysis of international quality management approaches in e learning. In U.-F. Ehlers \& J. M. Pawlowski (Eds.), Handbook on quality and standardization (pp. 1-13). Springer.

Wu, B., Hu, Y., Gu, X., \& Lim, C. P. (2016). Professional development of new higher education teachers with information and communication technology in Shanghai: A Kirkpatrick's evaluation approach. Journal of Educational Computing Research, 54(4), 531-562. https://doi.org/10.1177/0735633115621922

Wu, J. (2005). An investigation into application and development of ICT in China general higher education and its impact on the Librarians' roles in learning support: A case study of Shanghai Tongji University.

Xiao, L., Huang, H., \& Umpathy, K. (2005). A case study: Information and communication technologies adoption in higher education in China and India. AMCIS 2005 Proceedings, 44. http://aisel.aisnet.org/amcis2005/44

Zhao, J., \& Xu, F. (2010). The state of ICT education in China: A literature review. Front Education, 5(1), 50-77. https://doi.org/10.1007/s11516-010-0006-1 
Jember, S. T.

20 Consortia Academia Publishing (A partner of Network of Professional Researchers and Educators) 